\title{
CONTRIBUIÇÕES DE PAULO FREIRE E ÁLVARO VIEIRA PINTO PARA UMA EDUCAÇÃO CRÍTICA E HUMANIZADORA
}

DOI: $10.48075 /$ RI.V24I2.26241

Francisco Josimar Ricardo Xavier ${ }^{1}$ Jully Anne Almeida Lima²

Eliane Lopes Werneck de Andrade ${ }^{3}$

RESUMO: Neste artigo objetivamos discutir sobre educação crítica e humanizadora, costurando um diálogo entre os pensadores brasileiros Paulo Freire e Álvaro Vieira Pinto. Para isso, trazemos nossas perspectivas sobre algumas obras desses pensadores, a partir das quais constatamos que a construção dessa educação tem como premissa o reconhecimento de homens e mulheres enquanto sujeitos concretos, possuidores de saberes construídos em suas vivências, precisando apenas que suas consciências críticas sejam desenvolvidas. Alinhavamos a discussão apresentando as concepções de consciência ingênua e consciência crítica transpassadas nas obras dos dois pensadores, aprofundando as relações destas à constituição de uma educação crítica e humanizadora. Concluímos que as teses e reflexões de Paulo Freire e Álvaro Vieira Pinto são pertinentes ao contexto do Brasil atual, pois contribuem para o reconhecimento do outro e de suas diferenças, e no combate aos discursos conservadores e preconceituosos que ressurgiram com mais força nos espaços educativos e na sociedade.

Palavras-chave: Paulo Freire; Álvaro Vieira Pinto; Educação crítica e humanizadora.

\section{PAULO FREIRE AND ÁlVARO VIEIRA PINTO CONTRIBUTIONS TO A CRITICAL AND HUMANIZING EDUCATION}

ABSTRACT: In this paper we aim to discuss critical and humanizing education while creating a dialogue between two Brazilian intellectuals: Paulo Freire and Álvaro Vieira Pinto. We bring our

\footnotetext{
${ }^{1}$ Doutorando em Educação do Programa de Pós-Graduação em Educação da Universidade Federal Fluminense (UFF). E-mail: josimar xavier@id.uff.br

2 Doutoranda em Educação do Programa de Pós-Graduação em Educação da Universidade Federal Fluminense (UFF). E-mail: alimajully@gmail.com

${ }^{3}$ Doutoranda em Educação do Programa de Pós-Graduação em Educação da Universidade Federal Fluminense (UFF). Professora de Matemática da Rede Pública Estadual de Ensino do Rio de Janeiro. E-mail: eliane.lopes.mat@gmail.com
} 
perspectives about some of these intellectuals' production, from which we understand that the construction of this type of education has the premise of recognizing men and women as concrete subjects, who possess knowledge based on their experiences and only need to develop their critical consciousness. We aligned this discussion by presenting the conceptions of naive consciousness and critical consciousness from the works of these two intellectuals, strengthening their relations on the constitution of a critical and humanizing education. We emphasize that the ideas and thoughts of Paulo Freire and Álvaro Vieira Pinto are relevant to the current context of Brazil, in the sense that they contribute to the recognition of others' differences, as well as fighting against conservative and discrimination discourses that have emerged with more strength in educational spaces.

Key Words: Paulo Freire; Álvaro Vieira Pinto; Critical and humanizing education.

\section{INTRODUÇÃO}

Este artigo é fruto de discussões coletivas realizadas nas disciplinas "Teoria e Educação II" e "Alfabetização: conversações com Paulo Freire", do Programa de PósGraduação em Educação da Universidade Federal Fluminense (UFF) ${ }^{4}$. Na ocasião, enquanto discentes das duas disciplinas, aprofundávamos reflexões sobre os contextos históricos da educação brasileira, os percursos biográficos de pensadores do campo da Educação e algumas temáticas centrais abordadas em algumas de suas obras.

Dentre os pensadores estudados, optamos por empregar destaque a Paulo Freire e Álvaro Vieira Pinto pelo pioneirismo com que articularam a construção de uma educação em uma perspectiva efetivamente humana e democraticamente brasileira. As comemorações do centenário de Paulo Freire endossaram trazermos à tona as contribuições desse educador que, junto de Álvaro Vieira Pinto, via com bons olhos que uma futura ascensão política e social do Brasil poderia ser alcançada por meio da educação.

Como base de nossas discussões, neste artigo nos ancoramos especificamente nas obras "Sete lições sobre educação de adultos" (VIEIRA PINTO, 1982), "Educação como prática da Liberdade" (FREIRE, 1967), "Pedagogia do oprimido" (FREIRE, 2018) e "La educación: autocrítica de Paulo Freire e Iván Illich" (FREIRE; ILLICH, 1986), com as quais tivemos contato direto nas disciplinas estudadas.

A intimidade percebida nas relações construídas por estes dois educadores esclareceu-nos as proximidades das bases teóricas e filosóficas que constituem seus pensamentos. Em suas obras é perceptível a preocupação sobre a necessária construção de

\footnotetext{
${ }^{4}$ As referidas disciplinas são, nessa ordem, componentes obrigatório e eletivo do curso de Doutorado em Educação.
} 
uma educação que possibilitasse aos sujeitos das classes populares, sobretudo os trabalhadores e as trabalhadoras, ascenderem criticamente, contribuindo, assim, para suas comunidades.

A leitura de seus percursos biográficos nos levou a compreensão de que Paulo Freire e Álvaro Vieira Pinto construíram laços de amizade na militância de movimentos de luta pela educação. Fato que, somados às suas ideias, divergentes das concepções políticas dominantes do período da ditadura empresarial-militar no Brasil, Ihes rendeu a cassação dos direitos civis. Os dois pensadores tomaram rumos diferentes em seus exílios. De acordo com Freitas (1998), Álvaro Vieira Pinto foi inicialmente para a extinta lugoslávia, depois, por convite de Paulo Freire, que se encontrava no Chile, seguiu para este país, onde proferiu palestras sobre educação para o Ministério da Educação chileno, e trabalhou no Centro Latino-Americano de Demografia (CELADE) ${ }^{5}$.

A aproximação entre os pensadores neste período de exílio ocorreu simultaneamente ao momento em que vieram a público as obras "Educação como prática da liberdade" e "Pedagogia do Oprimido", ambas de Paulo Freire, publicadas respectivamente, em 1967 e 1968. De Álvaro Vieira Pinto, citamos "Ciência e existência”, publicada em 1969, e os manuscritos oriundos das palestras proferidas no âmbito do Ministério da Educação chileno, que originaram o livro "Sete lições sobre educação de adultos", publicado em 1982. Estas obras constituem acervo de literatura clássica dos cursos de Educação, nos permitem traçar as perspectivas da história da educação brasileira e trazem reflexões pertinentes ao contexto contemporâneo, das quais destacamos que sentidos de educação e de sujeitos buscamos construir em nossa sociedade.

Ao estudarmos estes dois pensadores, as discussões nas aulas também se encaminharam em entender as relações de influências entre si. Há muitos atravessamentos em seus percursos biográficos, nas comuns referências de outros intelectuais sobre seus pensamentos, além de suas bases teóricas e filosóficas estarem diretamente ligadas às correntes de pensamentos marxistas. Conceitos como "consciência crítica", "emancipação humana", "sujeitos concretos", "direitos concretos", "humanização", são emergentes nas obras de ambos. Esse atravessamento também se confirma na intimidade com que Paulo Freire, na publicação de "Educação como prática da liberdade" (FREIRE, 1967), atribuiu ao

\footnotetext{
${ }^{5}$ Álvaro Vieira Pinto só conseguiu entrar no Chile porque seria admitido como pesquisador do CELADE, contando com total apoio e influência de Paulo Freire (FREITAS, 1998).
} 
amigo Álvaro Vieira Pinto o adjetivo de "Mestre brasileiro"6, em reconhecimento por tamanha contribuição de seus pensamentos.

Alguns pesquisadores já tomaram Paulo Freire e Álvaro Vieira Pinto como centro de seus estudos, destacando, inclusive, suas biografias, análises de suas obras, dentre outros aspectos. Razão pela qual, não enveredamos esses caminhos, optando, assim, por endossar - lugar da contemporaneidade da produção desses intelectuais. Dessa maneira, esclarecemos que com este artigo objetivamos discutir sobre a contribuição dos pensamentos destes dois educadores para se construir uma educação crítica e humanizadora.

Tendo em vista que os ataques aos direitos sociais, à Ciência, ao pensamento pedagógico freireano e à educação em uma perspectiva democrática, vêm ocupando destaque na mídia e nos últimos governos federais do Brasil, consideramos importante retomar leituras de intelectuais que, entendendo a educação como força motriz possível de transformar o ser humano, pensaram a construção de uma sociedade brasileira menos desigual. Assim, neste artigo costuramos um diálogo entre Paulo Freire e Álvaro Vieira Pinto, centrando discussões sobre o processo de constituição de uma educação crítica e humanizadora, que atravessam algumas de suas obras.

Esclarecemos nossa perspectiva de que a educação se constrói nos diversos contextos sociais, trançada aos cotidianos e às diversidades culturais dos sujeitos que constituem a sociedade (BRANDÃO, 1984). Além disso, a entendemos como política pública, cabendo ao Estado investir nas suas diferentes formas, seja como ensino, nas escolas, como projeto social, em movimentos de cultura ou nas organizações sociais de luta pelos direitos humanos. Esperamos, com este artigo, compartilhar saberes com estudantes, colegas pesquisadores, professores e demais pessoas que reconhecem o valor que uma educação pública, laica e de qualidade, tem para a sociedade.

Na primeira seção do artigo lançamos luz sobre o movimento de deslocamento da consciência ingênua à consciência crítica, entendendo este como processo de construção de homens e mulheres em sociedade que, dentre outras contribuições, podem ampliar suas capacidades de entender e analisar criticamente suas realidades. A compreensão desse

\footnotetext{
${ }^{6}$ Adjetivo destacado na obra "Educação como prática da liberdade", em que Paulo Freire (1967) indica a leitura de "Consciência de Realidade Nacional", obra de Álvaro Vieira Pinto publicada em 1960 (Volume 1) e em 1961 (Volume 2).
} 
movimento encaminha à segunda seção, em que destacamos o entendimento da concepção de educação crítica, tão cara aos dois pensadores e tão necessária em nosso contexto atual. Finalizamos com a seção onde discutimos sobre a perspectiva de educação humanizadora defendida por Paulo Freire e Álvaro Vieira Pinto.

\section{DA CONSCIÊNCIA CRÍTICA À CONSCIÊNCIA INGÊNUA}

As leituras de Vieira Pinto (1982) e Freire (1967) nos permitiram compreender que a construção de uma educação democrática, como possibilidade de humanização de homens e mulheres em sociedade, pode ser efetivada mediante a conscientização desses sujeitos das problemáticas que os cerceiam. Essa conscientização seria, segundo os pensadores, encaminhada por uma tomada de consciência crítica pelos sujeitos, em que estes deixariam de lado sua consciência ingênua do mundo.

A consciência crítica, contudo, não é algo dado, mas se constitui em processo. Carece antes, do reconhecimento de homens e mulheres enquanto seres sociais que se encontram em estágio permanente de construção de seus pensamentos e conhecimentos. O reconhecimento de homens e mulheres como sujeitos politicamente alfabetizados. Entendemos que no movimento de deslocamento da consciência ingênua para a consciência crítica, há um percurso a ser trilhado que inclui as decisões políticas que vão sendo tomadas pelos sujeitos em relação às suas vidas e aos contextos em que estão inseridos.

Os conceitos "consciência crítica" e "consciência ingênua" foram cunhados por Álvaro Vieira Pinto na obra "Consciência e Realidade Nacional", publicada em 1961. Freire (1967, p. 105), tomando a referida obra como referência, destaca:

A consciência crítica "é a representação das coisas e dos fatos como se dão na existência empírica. Nas suas correlações causais e circunstanciais". "A consciência ingênua (pelo contrário) se crê superior aos fatos, dominandoos de fora e, por isso, se julga livre para entendê-los conforme melhor the agradar".

Os pensadores sinalizam haver diferenças entre essas duas consciências. A consciência ingênua desacredita a realidade e tem um limitado julgamento sobre fatos/acontecimentos. Esta seria manifestada, por exemplo, por meio de achismos ou argumentações simplistas. Vieira Pinto (1982, p. 59) a descreve da seguinte maneira: 
Consciência ingênua é aquela que - por motivos que cabe à análise filosófica examinar - não inclui em sua representação da realidade exterior e de si mesma a compreensão das condições e determinantes que a fazem pensar tal como pensa. Não inclui o mundo objetivo como seu determinante fundamental. Por isso julga-se um ponto de partida absoluto, uma origem incondicional, acredita que suas idéias vêm dela mesma, não provêm da realidade, ou seja, que têm origem em idéias anteriores.

A incapacidade de um pensar complexo e de entender que, mesmo as ideias mais específicas ou íntimas, estão no âmbito de uma totalidade maior, seriam, a nosso ver, características de uma consciência ingênua. Ao descrever "suas idéias vêm dela mesma", "têm origem em idéias anteriores", compreendemos que Vieira Pinto (1982) aponta que a ingenuidade em uma consciência se dá pela própria incapacidade de um sujeito explicar a proveniência de uma ideia ou pensamento. Há, assim, nesse tipo de consciência, a ingenuidade de que uma ideia veio de uma ideia, que veio de outra ideia, consistindo em uma cadeia regressiva de ideias ao infinito, o que tornaria um argumento ilógico e infundado.

Desta maneira, a conexão entre pensamento e argumentação, para imprimir defesa ou acusação sobre uma ideia/pensamento, seria a contextualização da realidade dos fatos que, entendida como concreta, seria o seu determinante fundamental. Vieira Pinto (1982, p. 60) destaca ainda que "a consciência ingênua pode refletir sobre si, tornar-se a si mesma como objeto de sua compreensão, porém, não chega a ser uma autoconsciência".

Analisamos, assim, que um sujeito dotado de consciência ingênua teria um pensamento limitado por ideias introspectivas e, por isso, consideraria suficiente suas próprias argumentações diante de uma discussão, por exemplo. Isso nos leva a entender que, a capacidade de pensar sobre o que pensa não seria uma classificação capaz de marcar a diferença determinante entre as consciências ingênua e crítica. Essa capacidade, muitas vezes, é usada para alimentar o egocentrismo de uma ingenuidade. A diferença entre elas, de acordo com Vieira Pinto (1982), é a capacidade que um sujeito tem de autorreflexão e autoconsciência crítica de si mesmo e de suas ações. Isso permite compreender que o homem e a mulher, reconhecendo-se como sujeitos inconclusos, dotados da capacidade de autoconsciência, podem desenvolver uma consciência crítica e, portanto, conhecedores dos caminhos que os levarão a ser mais. 
A consciência crítica tem como base as realidades circunstanciais e contextuais da existência mesma dos fatos/acontecimentos, bem como de suas representações, para, então, ser manifestada com propriedade por um sujeito. Vieira Pinto (1982, p. 60) a descreve da seguinte maneira:

Consciência crítica é a representação mental do mundo exterior de si, acompanhada da clara percepção dos condicionamentos objetivos que a fazem ter tal representação. Inclui necessariamente a referência à objetividade como origem de seu modo de ser, o que implica compreender que o mundo objetivo é uma totalidade dentro da qual se encontra inserida.

Entendemos que em uma consciência crítica a realidade é tomada como de existência concreta, e não subjetiva. Compreendê-la sob esta perspectiva é entender que homens e mulheres existem com o mundo, construindo-o constantemente e que, por isso, são sujeitos concretos, cujas subjetividades se reconstroem na concretude. Para Freire (1967) os homens e as mulheres são, em sua essência, concretos e politicamente alfabetizados, porque vivendo com o mundo, a consciência crítica está também em sua essência, precisando apenas ser desenvolvida, como processo que é a própria construção dela mesma.

A posição do homem e da mulher no mundo seria, para Freire (1967), a de travar relações com e na realidade concreta. Dentre estas, ele destaca "a relação específica que resulta no conhecimento, que expressa pela linguagem" (FREIRE, 1967, p. 104). Ainda segundo Freire (1967), as relações com a realidade independem da condição de ser ou não alfabetizado - ler e escrever os códigos linguísticos -, isso possibilita a compreensão de que homens e mulheres, porque diferentes entre si, constroem suas realidades, têm saberes específicos, não existindo, portanto, "ignorância absoluta, nem sabedoria absoluta" entre eles (FREIRE, 1967, p. 104).

Nestas perspectivas, entendemos que para os referidos pensadores, a construção de uma educação democrática coincide com a efetivação de práticas educativas que favoreçam a elevação do grau de consciência crítica dos homens e mulheres.

\section{SOBRE A CONCEPÇÃO DE EDUCAÇÃO CRÍTICA}


Álvaro Vieira Pinto e Paulo Freire defenderam uma educação que tomasse como ponto central a concepção de homem e mulher como sujeito inconcluso, que fosse capaz de contribuir para que se compreenda que ser mais seria um objetivo para cada sujeito estar no mundo. Tratava-se, em especial, de uma educação voltada ao povo constituinte da massa popular trabalhadora e explorada, que deveria, essencialmente, ser construída em regime de comunhão com ela.

Esta educação tomaria um "sentido amplo" (VIEIRA PINTO, 1982, p. 29), estando trançada por processos de aquisição das aprendizagens dos saberes das culturas próprias das experiências dos homens, das mulheres e dos saberes escolares. Estes últimos, por sua vez, apreendidos nos espaços das escolas, deveriam ter o papel de conscientização crítica das realidades concretas, das comunidades e dos contextos de mundo, de modo a despertar o senso de criticidade dos sujeitos.

Embebidos pelo sonho de que o povo poderia, em comunhão, reconhecer seus potenciais de lutas pelos seus direitos mais básicos, Paulo Freire e Álvaro Vieira Pinto projetaram uma educação emancipadora, que contribuiria para o progresso que se pensava ao Brasil de transição à segunda metade do século XX. Essa mesma educação evidenciava que os homens e as mulheres poderiam se potencializar criticamente a partir de suas próprias experiências de vida.

O que teríamos de fazer, uma sociedade em transição como a nossa, inserida no processo de democratização fundamental, com o povo em grande parte emergindo, era tentar uma educação que fosse capaz de colaborar com ele na indispensável organização reflexiva de seu pensamento. Educação que Ihe pusesse à disposição, meios com os quais fosse capaz de superar a captação mágica ou ingênua de sua realidade, por uma dominantemente crítica. Isto significava então colaborar com ele, o povo, para que assumisse posições cada vez mais identificadas com o clima dinâmico da fase de transição. Posições integradas com as exigências da Democratização fundamental, por isso mesmo, combatendo a inexperiência democrática. (FREIRE, 1967, p. 106).

A "fase de transição" faz referência ao projeto desenvolvimentista que alguns intelectuais pensaram para o Brasil depois dos governos de Getúlio Vargas. Este projeto foi articulado no governo de Juscelino Kubitschek, contou com apoio de vários intelectuais para pensar um projeto nacional educacional (FREITAS, 1998), entre estes estavam Álvaro Vieira 
Pinto e Paulo Freire, e outros que compuseram o então Instituto Superior de Educação Brasileira (ISEB) ${ }^{7}$.

Ainda que em parte dialogassem com o governo, o sentido de educação defendido pelos referidos pensadores, conforme explicitamos, tem como premissa a consciência crítica da massa trabalhadora. O desenvolvimento, em todos os seus aspectos, não viria como um passe de mágica. Em especial, o "desenvolvimento" da classe trabalhadora, que seria a libertação da situação de opressão, se daria de maneira gradativa, conforme o povo adquirisse o saber letrado e de cunho crítico. Era necessário, conforme sinaliza Freire (1967, p. 106) a superação da "captação mágica ou ingênua de sua realidade, por uma dominantemente crítica". E, portanto, essa educação seria alçada como processo democrático, de emancipação e ampla participação do povo. O "desenvolvimento", acenado na "transição" do Brasil, contribuiria para que o povo trabalhasse a conscientização de suas realidades.

O novo cenário que à época se aventava no país, era visto como algo positivo, mas também não passaria despercebido como momento que poderia tomar as paixões dos brasileiros, sobretudo daqueles das classes populares, como momento mágico. Assim entendido, a ideia de desenvolvimento, se tomada sob um enfoque ingênuo, poderia concorrer para maior aprofundamento da pobreza. Isso Freire $(1967$, p. 86$)$ deixou claro ao sinalizar:

\begin{abstract}
De uma educação que tentasse a passagem da transitividade ingênua à transitividade crítica, somente como poderíamos, ampliando e alargando a capacidade de captar os desafios do tempo, colocar o homem brasileiro em condições de resistir aos poderes da emocionalidade da própria transição. Armá-lo contra a força dos irracionalismos, de que era presa fácil, na emersão que fazia, em posição transitivante ingênua.
\end{abstract}

De maneira análoga, Vieira Pinto (1982, p. 49 [grifos no original]) assinala:

\footnotetext{
${ }^{7}$ O ISEB foi criado em 14 de julho de 1955, sob o Decreto no 57.608 assinado pelo então presidente João Café Filho, como órgão que substituiria o então Instituto Brasileiro de Economia, Sociologia e Política (IBESP), do qual participavam os intelectuais, Hélio Jaguaribe, Ignácio Rangel, Juvenal Osório Gomes, entre outros intelectuais que se encontravam para discutir, dentre outros pontos, os rumos da educação nacional, e pensar um projeto de educação realmente democrática e nacionalmente brasileira (FREITAS, 1998). Entre os objetivos do Instituto estava o de aplicar as categorias das ciências humanas e sociais para contribuir com o estudo e a promoção do desenvolvimento brasileiro.
} 
A finalidade da educação não se limita à comunicação do saber formal, científico, técnico, artístico, etc. Esta comunicação é indispensável, está claro, porém, o que se intenta por meio dela é a mudança da condição humana do indivíduo que adquire o saber. Por isso, a educação é substantiva, altera o ser do homem. A não ser assim, seria apenas adjetiva, mero ornamento da inteligência. $O$ homem que adquire o saber, passa a ver o mundo e a si mesmo deste outro ponto de vista. Por isso se torna um elemento transformador de seu mundo. Esta é a finalidade essencial da educação. Tal é a razão de que todo movimento educacional tenha consequências sociais e políticas.

Entendemos que os pensadores corroboraram sobre as ideias de que a construção de uma educação crítica não poderia ser ingenuamente entendida como uma "captação mágica", que viria atrelada aos discursos de desenvolvimento que ecoavam no Brasil. Era preciso, primeiramente, os homens e as mulheres se educarem criticamente, no sentido de compreender os problemas sociais, a própria condição histórica e social no mundo como massa trabalhadora para, então, juntos em comunhão, pensar uma educação com sentido mais próximo às suas realidades.

Conforme viemos discutindo, Paulo Freire e Álvaro Vieira Pinto entendiam como indispensável uma comunicação entre os saberes formais e os saberes das experiências dos sujeitos. Entretanto, para eles, os saberes formais precisavam ser somados à constituição da tomada de consciência crítica dos homens e das mulheres, no intuito de que compreendessem e assumissem de forma ativa, dentre outros aspectos, que as reflexões sobre as lutas por seus direitos e que a saída de suas situações de opressão era possível.

As leituras das produções desses pensadores nos permitem compreender que a educação, para ser crítica e dialética, precisa ser construída com o povo, pois, o compartilhamento das experiências dos sujeitos da massa popular amplifica seus sentimentos, emoções e realidades. Entretanto, não deve prender-se aos sentimentalismos dos sujeitos diante de seus contextos sociais, como elementos meramente fatalistas, mas como elementos capazes de serem transformados. Seria esta educação a grande possibilitadora da "mudança da condição humana" (VIEIRA PINTO, 1982, p. 49).

Entendemos que a concepção de educação crítica que atravessa as ideias de Paulo Freire, soma-se às de Álvaro Vieira Pinto, que a entendem como elemento propulsor das (re)construções das condições de subalternidade e opressão em que se encontravam os sujeitos das classes trabalhadores. Trata-se de uma educação crítica que objetiva 
transformar primeiramente homens e mulheres entre os seus pares, para que, cientes de suas lutas e da busca por seus direitos, transformem as sociedades, construindo um mundo mais humanizado.

\section{DIÁLOGOS SOBRE EDUCAÇÃO HUMANIZADORA}

Antes de iniciarmos os diálogos sobre educação humanizadora, identificaremos o inverso: a educação não orientada a uma concepção crítica, que dá margem à dominação e opressão daqueles que "possuem" o conhecimento e estimula a submissão dos que são julgados como os não detentores do saber: a educação que desumaniza.

A desumanização na educação acontece na concepção mais famosa adotada por Paulo Freire (2018, p. 83), como educação bancária, onde:

[...] os homens sejam vistos como seres da adaptação, do ajustamento. Quanto mais se exercitem os educandos no arquivamento dos depósitos que lhes são feitos, tanto menos desenvolverão em si a consciência crítica de que resultaria a sua inserção no mundo, como transformadores dele. Como sujeitos.

Isto é, nesta concepção há a transformação da pessoa humana em coisa, em objeto. As informações são depositadas nos educandos e estes recebem passivamente os "conhecimentos" como doação ou imposição de educadores-bancários que ensinam, disciplinam, falam, prescrevem, escolhem o conteúdo do programa, sabem, são detentores exclusivos do processo e, diferentemente da relação horizontal, com base no diálogo, permitem somente que o educando se encontre na posição de aprendiz, disciplinado, ouvinte, receitado, recebedor do conteúdo, aquele que não sabe (FREIRE, 1967). Em conformidade com Vieira Pinto (1982), esta educação bancária alienada, se fundamenta unicamente no conteúdo, que é visto ingenuamente como simples transmissão do conhecimento, ou seja, os depósitos da educação. Tal conteúdo será o que formará o educando a partir das concepções do educador, no que concerne ao tipo de homem e de mulher que convém ser formado.

Como destacado na seção anterior, Vieira Pinto (1982) chama a atenção para o fato de que a educação não pode limitar-se a ser conteudista, de maneira que se estabeleça somente em comunicar o saber formal, científico, técnico, artístico etc., ressaltando, 
contudo, que deve-se compreender que esta comunicação é indispensável, mas que diferentemente de ter por objetivo a transmissão, “[...] o que se intenta por meio dela é a mudança da condição humana do indivíduo que adquire o saber" (VIEIRA PINTO, 1982, p. 49). O referido pensador segue refletindo que objetivar esta mudança é uma das finalidades da educação. Freire (2018) aborda a construção da humanidade igualmente por este processo de comunicação na educação, onde homens e mulheres alcançam o poder de senso crítico, que se desenvolve no espaço educativo por meio do diálogo e da práxis, deixando de ser objetos e reconhecendo-se sujeitos da história. É a luta pelo ser mais.

A relação dialógica na educação defendida por Freire (1967) é baseada no respeito mútuo entre educador e educando, em uma relação horizontal de um com o outro, tendo como alicerce a fala, o diálogo, a escuta e a simpatia entre ambos. Assim, essa dialogicidade nos remete a um dos pressupostos da educação libertadora de não dissociação entre os sujeitos que interagem nas práticas educativas, pois, conforme o educador afirma, os homens e as mulheres são seres de relações, que para além de estarem no mundo, especialmente, estão "com o mundo", fator que "resulta de sua abertura à realidade" (FREIRE, 1967, p. 39).

Então, no caso da educação, pode-se relacionar a prática educativa a um tipo de recorte da realidade quando, nessa prática, a realidade objetiva de quem vivencia os processos de ensino e de aprendizagem é lida de forma intencional e discutida por ambos, educador e educandos, numa relação dialógica, crítica e problematizadora que propõe o desvelamento do mundo. Em nossa concepção, não somente dos educandos ou dos educadores, mas destes e daqueles, visto que as realidades de ambos estão ligadas pelas experiências que se entrelaçam de diferentes formas na vida em sociedade, o que permite, impulsiona e amplia a construção do conhecimento e a consciência sobre o mundo. Esta relação, demanda a responsabilidade político-social dos seres humanos, e do mesmo modo é evidenciada por Vieira Pinto (1982, p. 116):

A relação educacional é essencialmente recíproca, é uma troca de experiências, um diálogo. $O$ educador ingênuo não reconhece no aluno sua qualidade de sujeito e por isso julga ser o único sujeito do ato pedagógico. Com isso corrompe e deixa incompreendido tudo o que é essencial a este ato: o encontro de consciências. 
Desta forma, a atuação ingênua do educador acaba desumanizando tanto os educandos, quanto a si próprio, visto que na educação humanizadora, o educador identificase com os educandos e têm como orientação a humanização de ambos, sem doação conteudista, atuando no pensar autêntico, na profunda crença nos seres humanos e no seu poder de criação (FREIRE, 2018).

Nesse sentido, a perspectiva de humanização defendida pelos educadores, vai na contramão dos métodos educativos mantenedores de uma cultura hegemônica e dominante. Essa perspectiva destaca-se pela intenção de se pôr em prática uma educação mais democrática, com a valorização dos saberes de todos os envolvidos no processo educativo e com uma formação docente e discente mais consciente, humana e socialmente responsável.

Para Freire e Illich $(1986)^{8}$, a escola não está totalmente comprometida com as práticas de manutenção social, porque, como bem definiu Vieira Pinto (1982, p. 29, [grifos no original]) "A educação é processo pelo qual a sociedade forma seus membros à sua imagem e em função de seus interesses", contudo, a sociedade é permeada por muitas contradições, já que diferentes concepções de mundo e de educação sempre estão em disputa. Desta maneira, a escola é ainda vista como uma instituição privilegiada de educação bem como de antagonismos internos, por ser criação das classes dominantes para conduzir as sociedades sob seus interesses, e ter que carregar consigo uma imensa horda de trabalhadores em diferentes estágios de desumanização e humanização.

Além dessa gama de relações de poder que rege o tecido social, a própria condição da educação dá margem à interpretação de Paulo Freire sobre as disputas na escola. Para Vieira Pinto (1982, p. 30) a educação também, como um "fato social", possui natureza contraditória, porque busca simultaneamente a "incorporação" dos sujeitos ao modelo dominante da sociedade e o "progresso" no sentido de ruptura com as condições existentes no presente. Este pensador reconhece que a dupla intencionalidade entre incorporação e progresso é contraditória, ainda que seja ela geradora da plena realização da natureza humana. Mas essa forma divergente também foi expressa por ele como ato de "conservação" do conhecimento adquirido e ao mesmo tempo de "criação", de "crítica, negação e substituição do saber existente" (VIEIRA PINTO, 1982, p. 31).

\footnotetext{
${ }^{8}$ A tradução de Freire e Illich (1986) é nossa.
} 
Dessa forma, a educação não pode ser considerada neutra porque essas contradições remetem a diferentes interesses frente à distribuição dos conhecimentos entre os grupos sociais, geralmente antagônicos. A crítica que Paulo Freire tece sobre a não neutralidade da educação, característica principal da dimensão política dessa prática social, defendida por ele, fundamenta a percepção do necessário compromisso da educação para a transformação da sociedade contra a preservação do status quo existente, desumanizado e opressor.

Entendemos que a práxis que Paulo Freire e seus colaboradores realizaram nas rodas de alfabetização de adultos, os Círculos de Cultura, parte dos movimentos de educação popular que abrangeram diferentes grupos no período que antecedeu o golpe empresarialmilitar, criaram uma atmosfera em que se pode pensar nos conhecimentos formais com um caráter mais humanizado. Naquele episódio tão profícuo da alfabetização das camadas populares, o uso dos conhecimentos formais não foi renegado em prol dos conhecimentos populares, ao contrário, houve ali uma comunhão libertadora entre os conhecimentos e os aprendizados, de homens e mulheres nas distintas posições envolvidos no trabalho educativo e formativo, e também das diferentes práticas na busca pela alfabetização objetiva e política dos sujeitos.

A existência dessa interlocução entre os conhecimentos de naturezas diferentes foi (e é) possível, e é preciso juntar esforços nessa direção. Os sujeitos, quando trabalham os conhecimentos coletivamente, produzem novos conhecimentos ou, pelo menos, podem suspeitar que há possibilidades para se chegar a novos percursos formativos. No entanto, apenas o conhecimento de uma realidade como essa, ou de outra qualquer, não muda as práticas educativas e nem leva os sujeitos à emancipação.

Sobre uma compreensão ingênua do conhecimento da realidade como elemento fundante para a sua transformação, em um seminário realizado em Genebra, em 1975, Paulo Freire fez uma autocrítica sobre tal perspectiva conduzida por ele, anos antes, na escrita de "Educação como prática da Liberdade", destacou o referido intelectual:

Obviamente, o meu erro não foi reconhecer a importância fundamental de um conhecimento da realidade no processo de sua mudança, mas sim não ter aproveitado estes dois momentos distintos - o conhecimento da realidade e a tarefa de a transformar - em sua relação dialética. (FREIRE; ILLICH, 1986, p. 29). 
Este reconhecimento de incompletude, em razão de um pensamento "impregnado das condições históricas que the deram origem" (FREIRE, 1967, p. 3), conforme bem destacou Francisco C. Weffort, no prefácio de "Educação como prática da Liberdade", é importante para que se reconheça a relevância do amadurecimento do pensamento a partir das experiências, a partir da realidade concreta e das condições históricas para a viabilização do ser mais. As condições, que ainda não haviam possibilitado a Paulo Freire pensar uma dimensão maior sobre este aspecto do percurso para a humanização, foram reconfiguradas ao problematizar outro fator relevante para o alcance da humanização dos sujeitos: a conscientização. Vejamos o que ele comentou sobre isto:

Acrescento que nas obras Pedagogia do Oprimido e Ação Cultural pela Liberdade não assumo a mesma posição ao enfrentar o problema da conscientização. Minha própria prática, no tempo decorrido entre os dois últimos livros e o primeiro, me ensinou a descobrir realidades que antes eu não tinha oportunidade de ver. (FREIRE; ILLICH, 1986, p. 29).

Notemos que essa compreensão crítica da própria incompletude, identificada por Paulo Freire, é deveras salutar, porque contextualiza a importância da autocrítica e da compreensão sobre os próprios processos de mudanças de pensamento, que ocorrem em função dos acontecimentos e dos conhecimentos que os sujeitos vão construindo historicamente na experiência concreta da vida cotidiana, gerando uma observação crítica, impulsionada pelo pensamento sempre em transformação, que pode ser potencializada no diálogo democrático entre os sujeitos, quando este hábito vai se construindo nas práticas sociais.

A incompletude em Vieira Pinto (1982), pode ser percebida como uma relação entre conhecer algo em parte e perceber que o outro - em especial para ele e para nós, o educando - também possui natureza necessariamente culta, pois entendemos que tal compreensão, é uma das dimensões da relação dialógica horizontal entre os sujeitos nas práticas educativas. Um educador culto reconhece a própria incompletude e a dos educandos, e faz disso o mote para a ampliação do conhecimento de ambos. Conforme indica o referido pensador, "a qualidade de culto adquirida pelo educador lhe dá a noção de ser incompleto, inacabado, sabedor que ignora muito mais do que sabe. Seu valor positivo está em que tem consciência desse fato e se comporta em consonância com ele, não buscando negá-lo, ocultá-lo ou disfarçá-lo" (VIEIRA PINTO, 1982, p. 115). 
As ideias de Paulo Freire e de Álvaro Vieira Pinto, algumas construídas com seus pares, outras, com base na própria concretude de suas vidas em diferentes contextos econômicos, políticos e sociais de nossa história, constituem obras potentes, que em face da manutenção de expectativas e de situações de certa forma análogas àquelas que viveram em seu tempo, ainda se fazem presentes em nosso ideário como parte privilegiada do arcabouço fundamental para a compreensão e a formulação de estratégias e de produção de hábitos, na atual conjuntura em que vivemos.

Nos últimos anos, no Brasil, temos experimentado diferentes estágios dos processos presentes no binarismo alienação/emancipação, vividos pelas minorias políticas, como indígenas, mulheres, quilombolas, trabalhadores das camadas populares rurais e urbanos, perpassados pelas questões de classe social, e por outras complexidades como gênero, sexualidade, racismo etc., que têm conduzido frentes opostas de mobilização intensa, de lutas por pautas de transformações emancipadoras e críticas, fundamentadas inclusive no pensamento freireano, bem como de recrudescimento do conservadorismo e da intolerância contra elas.

Neste contexto, acentuadamente contraditório em razão das desigualdades sociais e econômicas no Brasil, damos um destaque especial ao Movimento Sem Terra (MST) para dialogarmos de forma tangencial sobre a educação no período atual. Reconhecemos que, além de ter importância indiscutível para a conscientização e emancipação política da população brasileira nas áreas rurais e urbanas, este Movimento social vivencia uma aproximação inevitável com a práxis freireana e, consequentemente, pelo que expomos ao longo de nossas argumentações, com a perspectiva vieirista, o que é ainda mais especial em função da homenagem a Paulo Freire e para iluminar nossas ações perante o enfrentamento da atual política de desmonte acelerado e estrutural da educação pública, em todos os níveis do sistema de ensino do país.

Conhecido mundialmente pelas intensas ações coletivas em prol da reforma agrária no Brasil, o MST também tem um papel relevante na condução da pauta pelo acesso à educação pública de seus integrantes e demais trabalhadores, subalternizados pelas políticas neoliberais que têm assolado as sociedades de capital dependente. Para os integrantes do Movimento, o acesso à educação é parte dos direitos básicos essenciais à construção da Reforma Agrária Popular. Neste sentido, o Setor de Educação do MST prima por objetivos como: 
[...] a erradicação do analfabetismo nas áreas, a conquista de condições reais para que toda criança e adolescente esteja na escola, isso implica na luta por escolas de ensino fundamental e médio dentro dos assentamentos, a capacitação dos professores para que sejam respeitados enquanto sabedores das necessidades e portadores da novidade de construir uma proposta alternativa de educação popular. O setor de Educação também atua na luta pela criação de políticas públicas educacionais para Educação de Jovens e Adultos (EJA) nos assentamentos e acampamentos, centrado no direito ao acesso à educação pública, gratuita e de qualidade, diminuindo o analfabetismo no campo brasileiro. Bem como na formação técnico profissionalizante de nível médio, em cursos superiores e de pósgraduação, por meio do Programa Nacional de Educação na Reforma Agrária (PRONERA), extinto pelo governo de Jair Bolsonaro em fevereiro de 2020. (MST, 2021, on-line).

Para alcançar seus propósitos, no âmbito da educação, uma das ações empreendidas pelo MST é a parceria com o Centro Paulo Freire de Estudos e Pesquisas, que tem organizado cursos com a temática freireana para formar seus integrantes, inclusive na modalidade Círculos de Cultura, e demais interessados em tais perspectivas. A luta destes militantes em diferentes frentes, bandeiras e em função do uso de instrumentos como a educação e a cultura exemplifica, de forma ímpar, a vontade de ser mais e as discussões de Vieira Pinto (1982) especialmente no que se refere à necessidade de educadoras e educadores compreenderem "a natureza necessariamente culta do povo para" sentirem-se desejosos de unirem-se "às massas de seu país". E, caso não tenham totalmente se dado conta, para melhor "compreender que o povo é a matriz de toda cultura, e que o saber, como conceito ou lei que reflete ou apreende um aspecto da realidade, não é em si mesmo cultura $^{9}$, senão que se torna tal quando representa um produto da consciência geral" (VIEIRA PINTO, 1982, p. 115), da consciência de mundo.

Para Freire (1967, p. 7), nos diálogos realizados em círculos de cultura, o "que fundamentalmente importa é que os sujeitos em aprendizagem, e concretos, se reconheçam a si próprios, no transcurso da discussão, como criadores de cultura". Consideramos este reconhecimento, tanto dos educandos bem como dos educadores, como um aspecto relevante para o desvelamento do mundo e para a materialidade da relação dialógica horizontal entre estes sujeitos, inclusive na escola. Esclarecemos que entendemos escola

\footnotetext{
${ }^{9}$ Para Vieira Pinto (1982, p. 115), a "cultura é por definição uma totalidade e por isso é sempre possuída pelo povo como unidade social".
} 
como um espaço de encontros entre pessoas, não são necessariamente encontros autoritários, daí que ocorre, inclusive, a disputa política no seu interior, mesmo que invisibilizada de diferentes formas pela estrutura dominante e vigente.

Como temos percebido, a cultura mais conservadora e intolerante que tem sido imposta mundialmente por grupos radicais, fomentada pelas políticas neoliberais das elites ocidentais, tem gerado uma problemática que não poderia estar limitada aos movimentos sociais, visto que têm sido intensas as disputas pelo domínio dos conteúdos das narrativas das professoras e dos professores. Além disso, em nosso país, este cenário foi se dando de forma legitimada pelas investidas políticas iniciadas com o projeto Escola Sem Partido, mais um estrangeirismo absorvido pelos entes envolvidos no desmonte da área educacional, que rechaçam os profissionais da educação que são capazes de conduzir seu trabalho de forma ética e laica, comprometidos com a formação humana dos estudantes.

Em nossa avaliação, surge um movimento de resistência por parte dos profissionais da educação a tais provocações e ações concretas das esferas governamentais. Ainda que de forma incipiente, esse movimento vem crescendo, de maneira incomodada, crítica e simultaneamente revigorado pelos pensamentos de educadores comprometidos com a educação enquanto política social, tais como Paulo Freire e Álvaro Vieira Pinto.

Nas mobilizações em prol da educação pública e sua não neutralidade, além dos profissionais da educação, têm participado estudantes e familiares das redes públicas de ensino básico com, dentre outros objetivos, reafirmar sua luta contra as investidas oportunistas em todas as instâncias públicas. Como exemplo, podemos citar as ocupações de escolas públicas, por estudantes secundaristas que defenderam seus direitos de ter educação de qualidade, de ter os currículos voltados às especificidades de suas comunidades e por mais investimento público.

Na rede pública de ensino fluminense, realidade em que estamos mais apropriados para falar, o enfrentamento tem se dado contra a implementação da política reformista do chamado "Novo Ensino Médio", que entendemos ser retrógrada e voltada para os interesses do capital. Em face da crise de saúde pública que vivemos atualmente, as discussões coletivas têm ocorrido por meio virtual, e tem como uma das pautas, esclarecer a comunidade escolar do significado de tal implementação nas escolas públicas, no sentido de imprimir uma defesa coletiva para que ela não ocorra nesta rede de forma acrítica e impositiva. 
Entendemos, sob as óticas freireana e vieirista, dialógicas, éticas e filosóficas de consciência crítica do mundo, de incompletude humana e de libertação, que essas resistências reforçam a importância de posicionamento político ativo-combativo e humanizador de educadoras e educadores dos diferentes níveis de ensino. Além do que, corrobora o compromisso dos mesmos com a (re)construção de um ensino escolar crítico, voltado à assunção dos saberes científicos, dos saberes outros de forma problematizadora e com viés mais humanista, pautados na dialogicidade horizontal para ampliação do conhecimento e transformação da realidade concreta das massas trabalhadoras subalternizadas, como potência para a humanização da sociedade atual de modo mais intenso e questionador.

Reconhecemos que defender uma educação pública de qualidade precisa de coragem e requer que os educadores e educadoras se coloquem em uma posição de resistência, como se colocaram Paulo Freire e Álvaro Vieira Pinto. Se pensarmos em uma educação crítica e humanizadora, é essencial entendermos que ela não vai ser dada. É preciso construí-la juntos, em comunhão, especialmente com a classe trabalhadora.

\section{CONSIDERAÇÕES FINAIS}

Neste artigo costuramos um diálogo entre as teses dos pensadores brasileiros Paulo Freire e Álvaro Vieira Pinto sobre educação crítica e humanizadora. Com ele, procuramos não só endossar a relevância de suas produções e pensamentos, mas também destacar as potencialidades que as discussões de ambos os pensadores têm ao contexto atual em que o Brasil encontra-se imerso.

Entendendo que uma educação para ser crítica e humanizadora necessariamente precisa reconhecer que os sujeitos envolvidos em sua construção são politicamente alfabetizados, discutimos a transição entre consciência ingênua e consciência crítica. Esta transição, conforme apresentado, se dá de forma gradual, nas vivências dos sujeitos e nos espaços educativos, tendo como premissa o reconhecimento primeiro das situações de subalternidades e dos problemas político-sociais que os cerceiam.

Ressaltamos que esse reconhecimento os possibilitaria, além de refletir sobre suas situações, um engajamento na luta coletiva por seus direitos básicos, entre estes, o de acesso à escolarização e aos saberes escolares. Não quaisquer formas de saberes escolares, 
mas os que, mediados por educadores e educadoras dotados de consciência crítica, os permitam aprofundar as reflexões acerca de suas situações e contribua para alcançarem seus objetivos individuais e coletivos. Em nossa perspectiva, essa mediação, orientada por educadores e educadoras tomados por consciência crítica, é um aspecto que, somado aos saberes das vivências dos sujeitos, e às suas consciências políticas, formam uma base para a construção de educação de cunho crítico.

Tecemos considerações frisando que uma perspectiva de educação humanizadora é apresentada pelos pensadores quando tratam do diálogo e das relações horizontalizadas entre os sujeitos que constituem os espaços educativos. Além disso, ela entende o educando como sujeito concreto, capaz de mudar sua realidade e dos outros à sua volta, propõe um diálogo com a diferença, e não tem a pretensão de hierarquizar os sujeitos, pelo contrário, busca reconhecer as potencialidades de cada um. Na contramão da educação bancária, que vê o educando como coisa, como sujeito inerte, a educação humanizadora reconhece os homens e mulheres como possuidores de saberes, e visa reforçar a luta coletiva em torno dos direitos sociais e da vida.

Ao perfazer as leituras das obras de Paulo Freire e Álvaro Vieira Pinto encontramonos diante de algumas reflexões, dentre as quais, o quanto é caro pensar e defender a construção de uma educação mais humana e de uma sociedade brasileira menos desigual, no sentido que ainda impera as perspectivas neoliberais e capitalistas, que tangenciam a educação como uma mercadoria e reforçam a reprodução das desigualdades sociais. Quão necessário se faz construir uma educação crítica, que seja capaz de confrontar a onda de pensamento conservador que se mostra cada vez mais forte nos espaços educativos. $E, O$ quanto uma educação nas perspectivas freireana e vieirista, de cunho crítico e humanizadora poderia dar novos ares e novos rumos ao nosso futuro.

\section{REFERÊNCIAS}

BRANDÃO, Carlos Rodrigues. O que é Educação. 11. ed. São Paulo: Brasiliense, 1984.

FREIRE, Paulo. Educação como prática da Liberdade. 1. ed. São Paulo: Paz e Terra, 1967.

FREIRE, Paulo; ILLICH, Iván. La educación: autocrítica de Paulo Freire e Iván Illich. 2. ed. Buenos Aires: Ediciones Búsqueda, 1986. 
FREIRE, Paulo. Pedagogia do oprimido. 66. ed. São Paulo: Paz e Terra, 2018.

FREITAS, Marcos Cezar de. Álvaro Vieira Pinto: a personagem histórica e sua trama. 1. ed. São Paulo: Cortez, 1998.

MST. Quem somos? MST. Movimento dos Trabalhadores Rurais Sem Terra. [On-line] Disponível em: https://mst.org.br/quem-somos/. Acesso em 17. mai. 2021.

VIEIRA PINTO, Álvaro. Sete lições sobre educação de adultos. 1. ed. São Paulo: Autores Associados: Cortez, 1982.

Recebido em 06 de novembro de 2020.

Aprovado em 25 de maio de 2021. 